\title{
Assessment of Halon-1301 as a groundwater age tracer
}

\author{
M. Beyer ${ }^{1,2}$, R. van der Raaij ${ }^{2}$, U. Morgenstern ${ }^{2}$, and B. Jackson ${ }^{1}$ \\ ${ }^{1}$ School of Geography, Environment and Earth Sciences, Victoria University of Wellington, Wellington, New Zealand \\ ${ }^{2}$ Department of Hydrogeology, GNS Science, Avalon, New Zealand
}

Correspondence to: M. Beyer (monique.beyer@ vuw.ac.nz)

Received: 21 November 2014 - Published in Hydrol. Earth Syst. Sci. Discuss.: 30 January 2015

Revised: 20 May 2015 - Accepted: 21 May 2015 - Published: 17 June 2015

\begin{abstract}
Groundwater dating is an important tool to assess groundwater resources in regards to their dynamics, i.e. direction and timescale of groundwater flow and recharge, contamination risks and manage remediation. To infer groundwater age information, a combination of different environmental tracers, such as tritium and $\mathrm{SF}_{6}$, are commonly used. However, ambiguous age interpretations are often faced, due to a limited set of available tracers and their individual restricted application ranges. For more robust groundwater dating multiple tracers need to be applied complementarily (or other characterisation methods need to be used to complement tracer information). It is important that additional, groundwater age tracers are found to ensure robust groundwater dating in future.

We have recently suggested that Halon-1301, a water soluble and entirely anthropogenic gaseous substance, may be a promising candidate, but its behaviour in water and suitability as a groundwater age tracer had not yet been assessed in detail. In this study, we determined Halon-1301 and inferred age information in 17 New Zealand groundwater samples and various modern (river) water samples. The samples were simultaneously analysed for Halon-1301 and $\mathrm{SF}_{6}$, which allowed for identification of issues such as contamination of the water with modern air during sampling. All analysed groundwater sites had also been previously dated with tritium, CFC-12, CFC-11 and $\mathrm{SF}_{6}$, and exhibited mean residence times ranging from modern (close to 0 years) to over 100 years. The investigated groundwater samples ranged from oxic to highly anoxic. All samples with available CFC data were degraded and/or contaminated in one or both of CFC-11 and CFC-12. This allowed us to make a first attempt of assessing the conservativeness of Halon-1301 in water, in terms of presence of local sources and its sensitivity towards
\end{abstract}

degradation, which could affect the suitability of Halon-1301 as groundwater age tracer.

Overall we found Halon-1301 reliably inferred the mean residence time of groundwater recharged between 1980 and 2014. Where direct age comparison could be made $71 \%$ of mean age estimates for the studied groundwater sites were in agreement with ages inferred from tritium and $\mathrm{SF}_{6}$ (within an uncertainty of 1 standard deviation). The remaining (anoxic) sites showed reduced concentrations of Halon-1301 along with even further reduced concentrations of CFCs. The reason(s) for this need to be further assessed, but are likely to be caused by sorption or degradation of the compounds. Despite some groundwater samples showing evidence of contamination from industrial or agricultural sources (inferred by elevated CFC concentrations), no sample showed a significantly elevated concentration of Halon-1301, which suggests no local anthropogenic or geologic sources of Halon-1301 contamination.

\section{Introduction}

Groundwater dating is a widely applied technique to determine groundwater flow parameters, e.g. recharge source and rate, flow direction and rate, residence time and volume. Age in itself is also increasingly used as a indication for quality and contamination risks (e.g. the New Zealand drinking water standard (Ministry of Health, 2008) and the European Water Framework Directive; EU Legislature, 2000).

Tracers, such as tritium, $\mathrm{SF}_{6}$ (Sulfur hexafluoride) and various CFCs (Chlorofluorocarbons), are commonly used to infer groundwater age of relatively young groundwater (recharged $<100$ years ago) by comparing their atmospheric history to their concentration found in groundwater. How- 
ever, all tracers have a restricted application range and face individual limitations, which can lead to ambiguous age interpretations (e.g. Allison and Hughes, 1978; Edmunds and Walton, 1980; Visser, 2009; Beyer et al., 2014a and references therein). As examples of these limitations, $\mathrm{SF}_{6}$ has natural sources (e.g. Busenberg and Plummer, 2000, 2008; Stewart and Morgenstern, 2001; Koh et al., 2007); CFCs have a stagnant input function (Bullister, 2011), have anthropogenic point sources (e.g. in industrial and horticultural areas) (e.g. Oster et al., 1996; Stewart and Morgenstern, 2001; Busenberg and Plummer, 2008, 2010; Cook et al., 2006) and are known to be degradable in anoxic environments (e.g. Lesage et al., 1990; Bullister and Lee, 1995; Oster et al., 1996; Shapiro et al., 1997). Ambiguous age interpretations can be inferred from tritium measurements due to similar rates of radioactive decay and decrease in atmospheric concentration, which leads to similar concentrations of tritium in groundwater recharged at different times. This is particularly true for the Northern Hemisphere, where concentrations in young groundwater are still elevated due to $\mathrm{H}$ bomb testing in the 1970s (Taylor et al., 1992; Morgenstern and Taylor, 2009; Morgenstern et al., 2010). Additional interpretation issues follow from both the seasonal variability of groundwater recharge and tritium in rain. In these situations the tritium recharge is often estimated using recharge weighting techniques (Allison and Hughes, 1978; Stewart and Taylor, 1981; Grabczak et al., 1984; Engesgaard et al., 1996; Knott and Olimpio, 2001, Morgenstern et al., 2010). These limitations with ambiguity and input uncertainty can be overcome by time series or multiple tracer observations. To allow for more robust age interpretation of (relatively young) groundwater in future, there is a need for additional, complementary groundwater age tracers.

We have previously and unexpectedly identified the presence of Halon-1301 $\left(\mathrm{CBrF}_{3}\right)$ in modern water samples. Our paper immediately following this discovery (Beyer et al., 2014b) has detailed this identification, has discussed known Halon-1301 properties and has suggested this compound might have potential as a new, complementary groundwater age tracer (for water recharged $<100$ years ago) to join the limited set of established compounds commonly used for this purpose. We have not inferred ages from Halon-1301 concentrations in that paper. However, we have provided a first insight into its performance by approximating Halon1301 ages derived from corrected CFC-13 data presented in Busenberg and Plummer (2008). In this work, we analysed Halon-1301 in a range of groundwater locations, inferred Halon-1301 ages from its concentration, and compared these to groundwater ages previously inferred from other tracers. We additionally commented on (and analysed where possible) the various properties of Halon-1301 that had not previously been assessed in detail but may affect its wide-scale applicability as an age tracer.

As discussed in that earlier paper (Beyer et al., 2014b), Halon-1301 appears to be a suitable groundwater age tracer,

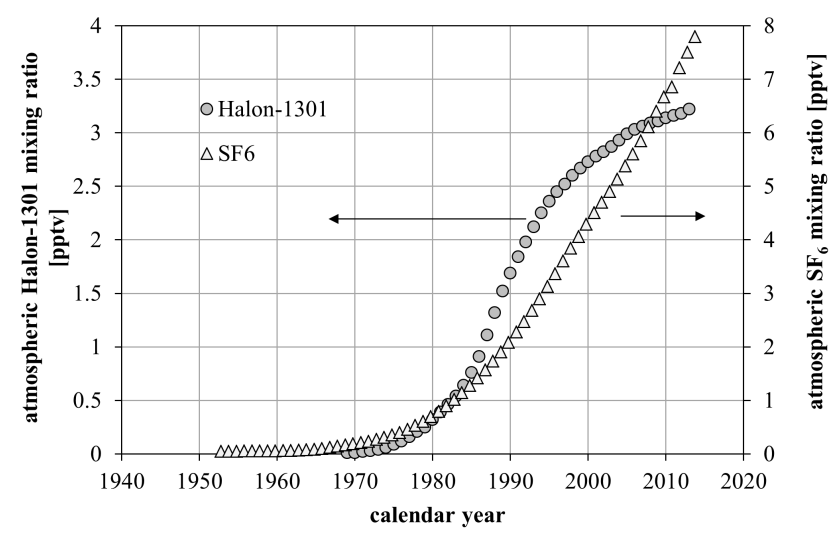

Figure 1. Historic records of Halon-1301 and $\mathrm{SF}_{6}$ atmospheric mixing ratios [pptv] (Newland et al., 2013; Butler et al., 1999; Thompson et al., 2004; Miller et al., 2008; Maiss and Brenninkmeijer, 1998).

since it is soluble in water (saturation: $30 \mathrm{mg} \mathrm{L}^{-1}$ at $20^{\circ} \mathrm{C}$; in contact with modern air (3.2 pptv): $7.5 \mathrm{fmol} \mathrm{L}^{-1}$ at $20^{\circ} \mathrm{C}$, $10 \mathrm{~m}$ elevation) (Deeds, 2008) and its increasing atmospheric concentration has been determined in the atmosphere since the 1970s by NOAA (National Oceanic and Atmospheric Administration) and AGAGE (Advanced Global Atmospheric Experiment) and data from 1969 to 1977 were reconstructed by Butler et al. (1999) (Fig. 1). Open questions remained regarding its conservativeness and contamination potential in groundwater environments. These are the following:

- Is Halon-1301 degrading like the structurally similar CFCs in anoxic groundwater (e.g. Plummer and Busenberg 1999) or due to hydrolysis (e.g. Butler et al., 1991; Sturges et al., 1991; Kanta Rao et al., 2003)?

- Does Halon-1301 sorb to organic material in soil or elute from sampling material as suggested for CFCs (Reynolds et al., 1990; Cook and Solomon, 1995)?

- Does its use as a fire suppression agent and occurrence as a by-product during pesticide (Fipronil) production lead to "local" contamination of groundwater?

- Can the interference of CFC-13 or other co-eluting compounds and Halon-1301 signals lead to overestimated Halon-1301 concentrations in water (potential co-eluting candidates are listed in Beyer et al., 2014b)?

- Most importantly, do the overall answers to these questions mean Halon-1301 can be used to reliably infer groundwater age in a wide variety of environments, and if so under what specific conditions, over what age ranges, etc.?

To answer these questions, we analysed Halon-1301 in 17 New Zealand groundwater samples and various modern 
(river) water samples. The analysis allowed for simultaneous determination of Halon-1301 and $\mathrm{SF}_{6}$ (Beyer et al., 2014b), which are both gaseous tracers with a similar behaviour in water. In this way, problems such as contamination due to contact with air during sampling or local (anthropogenic) sources could be identified.

All groundwater samples have been previously dated with tritium, $\mathrm{CFC}-12, \mathrm{CFC}-11$ and $\mathrm{SF}_{6}$. We determined piston and exponential piston flow ages for Halon-1301 and $\mathrm{SF}_{6}$, as inferred by matching the historic input to the determined concentrations in the groundwater samples. Comparison of inferred Halon-1301 piston flow and exponential piston flow mean residence times (MRTs) to relatively robustly inferred tritium and $\mathrm{SF}_{6}$ MRTs enabled for direct assessment of the performance of Halon-1301 as a groundwater age tracer. Because Halon-1301 and $\mathrm{SF}_{6}$ are both gaseous tracers, they are expected to show similar behaviour in the unsaturated zone. Gaseous tracers equilibrate with the atmosphere during transport through the unsaturated zone and therefore do not account for this unsaturated zone travel time. This contrasts with inferred tritium ages, which do account for travel time through the unsaturated zone. Comparison of age information inferred from tritium and four different gaseous tracers (SF 6 , Halon-1301, CFC-12 and CFC-11) allowed for assessment of unsaturated zones processes or potential contamination/degradation of Halon-1301. Since some of the anoxic samples clearly have shown evidence of CFC degradation, comparison of Halon-1301 from these samples enabled a first understanding of the potential for degradation of Halon-1301 in anoxic groundwater systems.

\section{Methodology}

\subsection{Water samples}

This study took advantage of the relatively well-defined age information of New Zealand groundwater inferred from time series tritium and $\mathrm{SF}_{6}$ (and $\mathrm{CFC}$ ) observations, particularly for confined aquifers (Morgenstern and Taylor, 2009, van der Raaij and Beyer, 2015). The inferred tritium ages were considered robust because of their well-defined input function (close proximity of our sampling sites to the high-resolution Kaitoke monitoring station) and because of long time series data in groundwater (Table 1). To enable a relatively comprehensive assessment of the potential of Halon-1301 as a groundwater age tracer, groundwater samples previously dated with tritium, $\mathrm{SF}_{6}$ and $\mathrm{CFCs}$ covering a wide range of mean residence times and including anoxic and oxic samples and samples with apparent contamination/degradation of CFCs were chosen. We analysed 35 groundwater samples from 17 different sites in the Wellington region from 3 different aquifer systems (Lower Hutt groundwater zone (LHGWZ), Wairarapa groundwater system and Wainuiomata aquifer) and 8 river and equilibrated tap water samples for

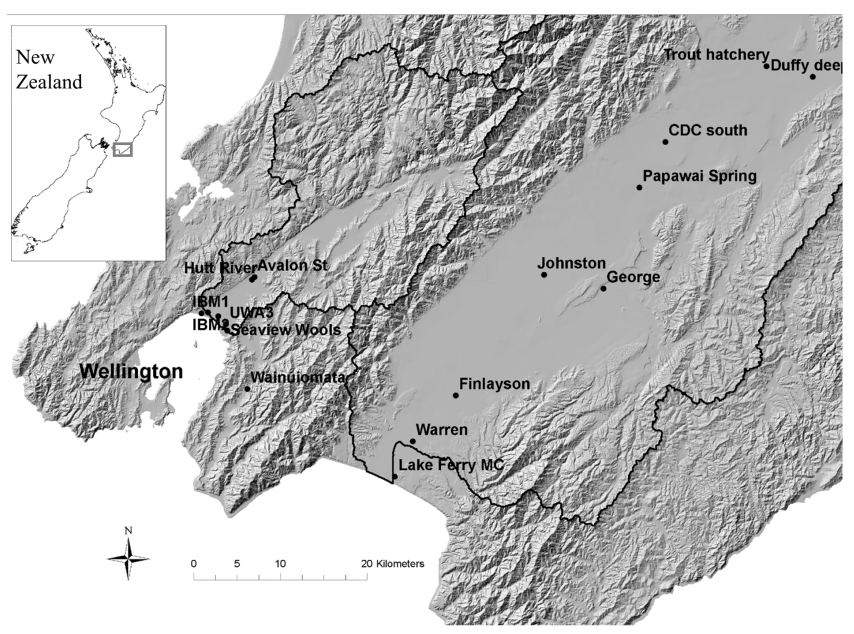

Figure 2. Groundwater wells and sampling locations in the Wellington region, New Zealand, are displayed as points; the black outlines represent the two catchments Hutt Valley (left catchment) and Wairarapa (right catchment).

Halon-1301 and $\mathrm{SF}_{6}$, simultaneously. Groundwater samples in the LHGWZ and river water samples were collected as triplicates, of which two were analysed directly after sampling and one was analysed after 7 weeks storage at $14^{\circ} \mathrm{C}$. One river water sample was analysed after 1.23 years of storage at $14{ }^{\circ} \mathrm{C}$. The location of the sampling sites and aquifer systems is shown in Fig. 2. The sampling sites, number of samples taken and corresponding aquifer systems are summarised in Table 1. Table 1 also includes the concentration of dissolved oxygen (DO), previously determined recharge temperature and amount of excess air (determined by Ar and $\mathrm{N}_{2}$ analysis) (Jones and Gyopari, 2006; Stewart and Morgenstern, 2001; Tidswell et al., 2012) and the number of previously taken CFC (CFC-11 and CFC-12), $\mathrm{SF}_{6}$ and tritium measurements. The groundwater systems are briefly described in the following.

Both the Wairarapa and the LHGWZ have formed in alluvial basins filled with greywacke gravel and marine deposits during glacial and interglacial periods. The Wairarapa is unconfined and is recharged both by rain and river infiltration while the LHGWZ is mostly confined and mainly river recharged. More detailed descriptions of the Lower Hutt groundwater system can be found in Grant-Taylor (1967), Reynolds (1993) and Gyopari (2014) and of the Wairarapa groundwater system in Begg et al. (2005) and Jones and Gyopari (2006). The Wainuiomata aquifer is a shallow, unconfined aquifer, which has formed in an alluvial valley filled with alluvial gravel and sand (Jones and Barker, 2005; WRC, 1993).

For determination of Halon-1301, a sampling procedure similar to the standard procedure for determination of water soluble gaseous tracers, such as $\mathrm{SF}_{6}$ and $\mathrm{CFCs}$ was followed. To ensure the sampling of fresh unexposed ground- 
Table 1. Summary of water samples analysed in this study: site name, amount of duplicates analysed, associated groundwater (GW) system, recharge temperature and excess air determined from noble gas analysis, dissolved oxygen (DO) and number of available CFC, tritium and $\mathrm{SF}_{6}$ data.

\begin{tabular}{|c|c|c|c|c|c|c|c|c|}
\hline $\begin{array}{l}\text { Site } \\
\text { name }\end{array}$ & $\begin{array}{c}\text { No. of water } \\
\text { samples }\end{array}$ & $\begin{array}{l}\text { Groundwater } \\
\text { system }\end{array}$ & $\begin{array}{r}\text { Recharge } \\
T\left[{ }^{\circ} \mathrm{C}\right]\end{array}$ & $\begin{array}{r}\text { Excess air } \\
{\left[\mathrm{mL}(\mathrm{STP}) \mathrm{L}^{-1}\right]}\end{array}$ & $\begin{array}{r}\text { DO } \\
{\left[\mathrm{mg} \mathrm{L}^{-1}\right]}\end{array}$ & $\begin{array}{c}\text { No. of } \mathrm{SF}_{6} \\
\text { data }\end{array}$ & $\begin{array}{c}\text { No. of CFC } \\
\text { data }\end{array}$ & $\begin{array}{c}\text { No. of tritium } \\
\text { data }\end{array}$ \\
\hline Wainuiomata & 3 & Wainuiomata & $10.7 \pm 1.8$ & $0.6 \pm 0.9$ & 4.17 & 2 & 1 & 2 \\
\hline Avalon Studio & 3 & $\mathrm{LHGWZ}^{+}$ & $14.2 \pm 1.9$ & $-0.7 \pm 0.9$ & 4.82 & 1 & 2 & 4 \\
\hline IBM 2 & 3 & LHGWZ $^{+}$ & $12.3 \pm 1.9$ & $1.0 \pm 0.8$ & 0.31 & 4 & 3 & 9 \\
\hline Seaview Wools & 3 & $\mathrm{LHGWZ}^{+}$ & $15.8 \pm 2.1$ & $2.3 \pm 0.9$ & 0.22 & 2 & 1 & 3 \\
\hline River water (Hutt River) & 4 & $\mathrm{LHGWZ}^{+}$ & $15.4 ; 12.3$ & $2.9 \pm 1.8^{\mathrm{a}}$ & 10.8 & 1 & 1 & 1 \\
\hline IBM 1 & 3 & LHGWZ $^{+}$ & $10.4 \pm 1.5$ & $0.8 \pm 0.8$ & 0.29 & 3 & 2 & 4 \\
\hline UWA3 & 3 & $\mathrm{LHGWZ}^{+}$ & $12.1 \pm 1.8^{\mathrm{a}}$ & $2.9 \pm 1.8^{\mathrm{a}}$ & $4.19 ?$ & 2 & 1 & 3 \\
\hline Shandon GC & 3 & LHGWZ $^{+}$ & $9.7 \pm 1.5$ & $0.3 \pm 0.8$ & 0.11 & 3 & 2 & 1 \\
\hline Buick St & 3 & LHGWZ $^{+}$ & $10.8 \pm 1.2$ & $0.6 \pm 0.6$ & 0.26 & 1 & 2 & 2 \\
\hline Duffy deep & 1 & Wairarapa & $14.0 \pm 0.1$ & $2.1 \pm 0.2$ & $2.28^{\mathrm{b}}$ & 2 & 1 & 1 \\
\hline CDC south & 1 & Wairarapa & $10.7 \pm 1.6$ & $2.0 \pm 0.8$ & $1.16^{\mathrm{b}}$ & 3 & 2 & 3 \\
\hline George & 1 & Wairarapa & $20.0 \pm 2.4$ & $5.5 \pm 0.9$ & 0.02 & 2 & 1 & 2 \\
\hline Finlayson & 1 & Wairarapa & $20.7 \pm 1.5$ & $-3.4 \pm 0.8$ & 0.02 & 2 & 1 & 1 \\
\hline Warren & 1 & Wairarapa & $9.4 \pm 1.8$ & $3.0 \pm 1.0$ & 0.22 & 1 & 0 & 1 \\
\hline Johnston & 1 & Wairarapa & $10.3 \pm 1.8$ & $0.1 \pm 1.0$ & 0.26 & 2 & 1 & 3 \\
\hline Trout hatchery & 1 & Wairarapa & $14.2 \pm 1.5$ & $-0.3 \pm 0.8$ & 6.12 & 2 & 1 & 0 \\
\hline Papawai Spring & 1 & Wairarapa & $12.7 \pm 1.5$ & $-0.4 \pm 0.8$ & 5.52 & 2 & 1 & 1 \\
\hline Lake Ferry MC & 1 & Wairarapa & $11.4 \pm 1.7$ & $2.4 \pm 0.8$ & 2.84 & 1 & 0 & 2 \\
\hline equilibr. water & 4 & - & $14.4 ; 19.8$ & $\mathrm{n} / \mathrm{a}$ & - & 1 & 1 & $\mathrm{n} / \mathrm{a}$ \\
\hline
\end{tabular}

a If no data are available for this site, the average $\mathrm{NZ}$ recharge temperature of $12.1 \pm 1.8^{\circ} \mathrm{C}$ and/or average $\mathrm{NZ}$ excess air $2.9 \pm 1 \mathrm{~mL}(\mathrm{STP}) \mathrm{L}^{-1}$ (van der Raaij and Beyer, 2015 ) are used; $\mathrm{LHGWZ}$

${ }^{+}$Lower Hutt groundwater zone; ${ }^{b}$ groundwater shows considerable amount of methane and is considered as anoxic, despite relatively high oxygen concentration; n/a stands for not applicable.

water (i.e. not the water stagnating in the dead volume of the well), the well was flushed at least 3 times of its volume and until conductivity, $\mathrm{pH}$ and DO stabilised. (Daughney et al., 2006). To avoid alteration of Halon-1301 concentrations with UV light and contamination or adsorption of the gas tracers (Halon-1301 and $\mathrm{SF}_{6}$ ) from/onto the sampling material, only brown borosilicate glass bottles and nylon tubing were used and the use of PTFE/Teflon or other fluorine baring plastics was avoided (Reynolds et al., 1990; van der Raaij and Beyer, 2015). To avoid contamination of the samples with modern air, sampling was carried out under rigorous exclusion of air by inserting a nylon tube to the bottom of the sampling bottle and filling it from the bottom. Then the bottle was allowed to overflow, so that the water volume was replaced by several bottle volumes. The bottle was quickly capped and checked for presence of bubbles and if necessary the sampling process was repeated until no bubble is present.

River water and a variety of equilibrated (at close to constant temperature) tap water samples were taken as representative modern water sample and to verify solubility data. This method presupposed no contamination by $\mathrm{SF}_{6}$ or Halon1301 from the air within our facilities, surrounding environment or river sampling locations, which seemed reasonable, due to the lack of sources of these compounds in the surrounding areas. Air samples were regularly analysed to confirm the lack of elevated $\mathrm{SF}_{6}$ and Halon-1301 concentrations in our facilities.

\subsection{Analytical system}

The water samples were purged with ultra-pure (analytical grade) nitrogen gas in a vacuum sparge chamber (Busenberg and Plummer, 2000). Purging with nitrogen at a flow rate of $70 \mathrm{~mL} \mathrm{~min}^{-1}$ for $18 \mathrm{~min}$ was carried out to ensure complete degassing of the water sample in regards to removal of $\mathrm{SF}_{6}$ and Halon-1301. The stripped gas then passed through a drying column $(\mathrm{NaOH}$ coated silica) to remove residual moisture and $\mathrm{CO}_{2}$ to avoid interference in the detection system. To ensure consistent amounts of water samples were purged, the sparge chamber was filled until the filling mark $(0.955 \mathrm{~L})$ or the weight of the water sample was determined. If applicable, temperature and headspace volume were determined. Standard gas samples were pushed through a loop of known volume $(9.97 \pm 0.02 \mathrm{ml}$ or $0.502 \pm 0.001 \mathrm{~mL}$, in the following referred to as 10 and $0.5 \mathrm{~mL}$, respectively) and the temperature and pressure were recorded to determine the amount of standard gas analysed.

The samples (standard gas and purged gas from water samples) were then simultaneously analysed for Halon-1301 and $\mathrm{SF}_{6}$ using a gas chromatograph with attached electron capture detector (GC/ECD) set-up including two cryogenic traps for pre-concentration (Busenberg and Plummer, 2008; Beyer et al., 2014b). The analytical set-up also allowed for simultaneous determination of CFC-12 (Busenberg and Plummer, 2008; Beyer et al., 2014b). However, an appropriately concentrated standard gas is needed to establish its calibra- 
tion curve. CFC- 12 concentrations and inferred CFC-12 ages were therefore not determined in the study.

In the following the determination of Halon-1301 and $\mathrm{SF}_{6}$ concentrations in water samples and resulting recharge year are described, which involves the determination of a calibration curve, solubility and where required excess air and headspace correction.

\subsection{Calibration}

The amount of Halon-1301 and $\mathrm{SF}_{6}$ in all groundwater samples were determined by establishing a calibration curve (least-square fit, forced through $0 / 0^{1}$ ) with approximately $10 \mathrm{~mL}$ certified air standard at various pressures. The certified air standard contained $3.27 \pm 1.55$ ppt Halon-1301 and $7.53 \pm 0.81$ ppt $\mathrm{SF}_{6}$ among other gases (supplied by the Scripps Institution of Oceanography in 2011). A calibration curve was established every day before measurement commenced, since the performance of the GC/ECD can change from day to day, due to fluctuations in the environment (e.g. temperature) or aging of the material (e.g. column fill). Because Halon- 1301 concentrations in $10 \mathrm{~mL}$ calibrated air standard did not sufficiently cover concentrations obtained in modern water samples, another standard gas containing $3.16 \pm 0.3$ ppb Halon-1301 and $1.02 \pm 0.1 \mathrm{ppb} \mathrm{SF}_{6}$ (prepared by New Zealand Industrial Gases (NZIG)) was used in a smaller standard loop of approximately $0.5 \mathrm{~mL}$ at various pressures. Additionally, tap water samples ranging from 1 to $15 \mathrm{~L}$ volume and $10 \mathrm{~mL}$ modern air samples at pressures from 1 to 3.5 bar were analysed to assess the linearity of the ECD signal towards Halon-1301 concentrations in the concentration range obtained in old to modern $1 \mathrm{~L}$ water samples. If linearity was found, then previously determined calibration curves (using the calibrated air standard) were linearly upscaled to estimate Halon-1301 concentrations in water. This was relevant for all groundwater samples for which calibration curves have been established at the time of measurement with calibrated air only. We were aware that this introduced additional uncertainty which we took into account (see Results section).

After determination of the molar amount of Halon-1301 (and $\mathrm{SF}_{6}$ ) in a $1 \mathrm{~L}$ water sample purged in the vacuum sparge chamber, its equivalent atmospheric molar ratio at time of equilibrium (for groundwater samples at recharge) was determined using the solubility relationship (Henrys law, de-

\footnotetext{
${ }^{1}$ We analysed blank samples (only containing $\mathrm{N}_{2}$ ) which indicated 0 signal for SF6 and Halon-1301. Additionally, the statistical difference between the intercept of the calibration curves for SF6 and Halon-1301 (when not forced through 0/0) were not significant (at $99 \%$ confidence). The intercept of the calibration curve was therefore considered insignificantly different from 0 ; hence, the calibration curve was forced through $0 / 0$ to simplify the calibration procedure and to ensure 0 signal is interpreted as a concentration of 0 (fmol L ${ }^{-1}$, e.g.). This procedure is following the suggestion of Helsel and Hirsch (2002) and Caulcutt and Boddy (1983).
}

scribed in Supplement Sect. S1). In contrast to the solubility of $\mathrm{SF}_{6}$, which has been well studied and directly measured (Bullister, 2002; Wilhelm et al., 1977, Table 2), the solubility parameters of Halon-1301 have only been estimated by Deeds (2008) using the solubility estimation methods of Meylan and Howard (1991) and Meylan et al. (1996). Actual solubility measurements of Halon-1301 are not available in literature (according to our searches and further backed up by personal communication with Daniel Deeds, 6 March 2015). We used modern (equilibrated tap and river) water to estimate solubility to validate the solubility estimates. If applicable, the amount of Halon-1301 (and $\mathrm{SF}_{6}$ ) in the water sample was corrected for headspace and/or excess air (previously determined by dissolved $\mathrm{Ar}$ and $\mathrm{N}_{2}$ determination; Heaton and Vogel, 1981), also described in detail in Supplement Sect. S1.

\subsection{Determination of recharge year}

To infer the recharge year or residence time of the groundwater, the equivalent partial pressure of Halon-1301 and $\mathrm{SF}_{6}$ in the atmosphere at time of recharge (determined as described above) was compared to their historic atmospheric records (illustrated in Fig. 1). Southern hemispheric atmospheric $\mathrm{SF}_{6}$ records (Cape Grim station) are available at the NOAA (National Oceanic and Atmospheric Administration) (http://www.esrl.noaa.gov/gmd/; Thompson et al., 2004) and CDIAC (Carbon Dioxide Information Analysis Center) websites (Miller et al., 2008); data from 1973 to 1995 have been reconstructed by Maiss and Brenninkmeijer (1998). Southern hemispheric (Cape Grim) atmospheric Halon-1301 concentrations have been summarised and smoothed by Newland et al. (2013). Data from 1969 to 1977 have been reconstructed by Butler et al. (1999). We assumed that Halon-1301 concentrations are well mixed across the atmosphere of the Southern Hemisphere as suggested by Montzka and Fraser (2003) and Butler et al. (1998) and local sources of Halon-1301 are lacking as indicated by regular analysis of local air in this study, so that southern hemispheric atmospheric concentrations could be used to estimate concentrations of Halon-1301 in recharge.

Although a comprehensive analysis of potential local sources has not yet been carried out, studies such as that by Barletta (2011) in Los Angeles, USA, have not found local enhancement of Halon-1301 in city environments. We are aware of only one study that has found unusual fluctuations of Halon-1301 in the atmosphere: in two stations in Poland, at Krakow and Kasprowy Wierch stations. The research group is still investigating reasons, but speculate it may be attributed to local sources from close-by city/industry environments (Bartyzel, 2015).

In simple terms the recharge year can be found when observed (equivalent) atmospheric concentrations match historic atmospheric concentrations. This can be done using a simple "lookup" table to infer the piston flow recharge year. However, misleading age interpretations can be obtained 
Table 2. Reported solubility parameters for Halon-1301 and $\mathrm{SF}_{6}$.

\begin{tabular}{llrrr}
\hline Compound & Reference & \multicolumn{3}{c}{ Parameters for Henry solubility coefficient } \\
\cline { 3 - 5 } & & A & B & C \\
\cline { 3 - 5 } & & -96.5975 & 139.883 & 37.8193 \\
\hline $\mathrm{SF}_{6}$ & Bullister et al. (2002) & -92.9683 & 140.1702 & 36.3776 \\
Halon-1301 & Deeds (2008) & -91.878 & 139.001 & 35.478 \\
\hline Halon-1301 & This study* & & \\
\hline
\end{tabular}

* Solubility parameters for Halon-1301 estimated in this study with an uncertainty of $10 \%$.

when using piston flow assumptions, which do not take account of mixing processes of groundwater in the aquifer or during sampling (e.g. Eberts et al., 2012). Therefore, lumped parameter modelling is often used to infer an age distribution and with it the MRT of the groundwater samples from tracer observations (Małoszewski and Zuber, 1982; Jurgens et al., 2012). In this study we adopt the commonly used exponential piston flow modelling (EPM), which had previously been found to best represent tritium (time series) and $\mathrm{SF}_{6}$ observations in the studied groundwater. EP modelling was carried out using TracerLPM software (USGS) (Jurgens et al., 2012). For 1 point tracer observations, as obtained for Halon-1301 and $\mathrm{SF}_{6}$ in this study, a range of EPMs with various exponential to total flow ratios (referred to as $1 / n ; n$ has been defined as ratio of total to exponential flow by Małoszewski and Zuber, 1982) could be fit to the tracer observation. Since the mixing parameter could not be adequately constrained with a 1 point measurement of Halon-1301 and $\mathrm{SF}_{6}$, we constrained their $1 / n$ ratio to the $1 / n$ ratio previously inferred from tritium (time series) observations. We assumed this approach was adequate under the assumption of steady state at each sampling location, which has been indicated by assessment of time series hydrochemistry data (using trend and seasonality analysis). MRTs (using EPM or piston flow - PM) inferred from $\mathrm{SF}_{6}$ and Halon-1301 concentrations were subsequently compared to previously determined MRTs inferred from tritium. We also commented on observed Halon-1301 concentrations in regards to previously observed degradation or contamination with CFCs (CFC-12 and CFC-11) in these wells.

\subsection{Analytical uncertainty}

Due to uncertainties related to the analytical procedure (calibration, analysis, etc.), the inferred recharge year and mean residence time (from Halon-1301 and $\mathrm{SF}_{6}$ concentrations) can only be constrained to an age range. To determine the overall relative uncertainty, the Eurachem /CITAC (Cooperation on International Traceability in Analytical Chemistry) Guide CG4 (Ellison and Williams, 2012) was followed. This guide recommends the method described in Kragten (1994), which also implies a sensitivity analysis. The standard measurement error was determined as the total of the following (independent) uncertainties:

$u_{\text {total }}(x)=\sqrt{u 1^{2}+u 2^{2}+u 3^{2}+u 4^{2}+u 5^{2}+u 6^{2}+u 7^{2}}$,

where $u 1$ is uncertainty from least-square regression (calibration curve), $u 2$ uncertainty in standard gas concentration, $u 3$ repeatability error from relative standard deviation of replicates, $u 4$ uncertainty related to correction for headspace, $u 5$ uncertainty related to correction for excess air, $u 6$ uncertainty in recharge temperature and $u 7$ uncertainty in solubility.

Replicate samples were analysed to determine the repeatability of the analysis. The absolute standard deviation is defined as

$\mathrm{ASD}_{i}=\sqrt{\frac{\left(\sum\left[\left(a_{i}-\bar{x}_{i}\right)\right]^{2}\right)}{n-1},}$

where $a_{i}-\bar{x}_{i}$ is the difference between the concentrations obtained for one of the replicate samples $a_{i}$ with overall mean value $\bar{x}_{i}$ for $n$ samples and $i$ number of replicates. The overall relative standard deviation can then be determined as median of all replicate samples:

$D_{i}=\sum\left(\frac{\mathrm{ASD}_{i}}{\bar{x}_{i}}\right)$

The limit of detection (LOD) and limit of quantification (LOQ) were determined by taking into account the slope and standard deviation (SD) of the calibration curve (Shrivastava and Gupta, 2011):

$\mathrm{LOD}=3.3 \frac{\mathrm{SD}}{\text { slope }}$ and LOD $=10 \frac{\mathrm{SD}}{\text { slope }}$

Nomenclature: in the following the various forms of modern water (river and equilibrated tap water) are summarised and referred to as one sample type, namely modern water. Hence, all comparisons are made in relation to a total of 18 (17 groundwater +1 modern water) samples. The term age or recharge year refers to an age or recharge year distribution, which is a function of MRT and mixing parameter (e.g. ratio of exponential to total flow for the EPM). 

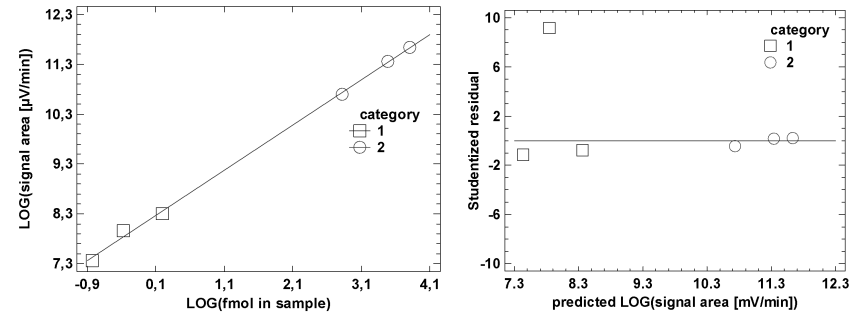

Figure 3. Calibration curve (LEFT) and residual plot (RIGHT) for Halon-1301 using $10 \mathrm{~mL}$ calibrated air standard (category 1) and $0.5 \mathrm{~mL}$ highly concentrated Halon-1301 standard (NZIG) (category 2).

\section{Results and discussion}

\subsection{Calibration curve}

Figure 3 illustrates the calibration curves of Halon-1301 obtained with the calibrated air standard (Scripps) and highly concentrated Halon-1301 standard (NZIG) with a nearly linear response of the ECD towards Halon-1301 concentration in the concentration range obtained for groundwater samples (signal up to $30 \mathrm{mV} \mathrm{min}^{-1}$ for modern water). Additional analysis of modern air at pressures ranging from 1 to $3.5 \mathrm{bar}$ and analysis of water samples of 3 to $15 \mathrm{~L}$ (Fig. 4) confirmed the nearly linear response of the ECD towards Halon-1301 concentrations in this concentration range. Only for very high amounts of Halon-1301 (signals of approximately 1 order of magnitude higher than obtained in modern water) did the quadratic regression fit slightly better than the linear regression. Given this evidence of a linear signal response up to concentrations obtained in modern water, we linearly upscaled the calibration curve of Halon-1301 obtained with the calibrated air standard to estimate concentrations of Halon1301 in all groundwater samples. Using this approach we introduced additional uncertainty, which we took account of during discussion of the inferred MRTs (for further detail see Sect. 3.4: "Assessment of inferred Halon-1301 ages" and Supplement Sect. S2 "Assessment of elevated Halon-1301 ages").

\subsection{Uncertainty}

The analysis allowed for an average repeatability of $3.6 \%$ for Halon-1301 (2.8\% for $\left.\mathrm{SF}_{6}\right)$ and $9.8 \%$ (6.9\% for $\left.\mathrm{SF}_{6}\right)$ average standard deviation of the calibration curve. On average the overall analytical uncertainty in an average ${ }^{2} \mathrm{New}$ Zealand groundwater sample was $4.7 \%$ for Halon-1301 $\left(9.0 \%\right.$ for $\left.\mathrm{SF}_{6}\right)$. This led to a larger uncertainty in inferred piston flow age for waters recharged before 1975 and after

\footnotetext{
${ }^{2}$ A detailed study in New Zealand has shown groundwater samples have on average a recharge temperature of $12.1 \pm 1.8^{\circ} \mathrm{C}$, $2.9 \pm 1 \mathrm{~mL}(\mathrm{STP}) \mathrm{kg}^{-1}$ excess air and a headspace volume of $0.5 \pm 0.05 \mathrm{~mL}$ (van der Raaij and Beyer, 2015).
}
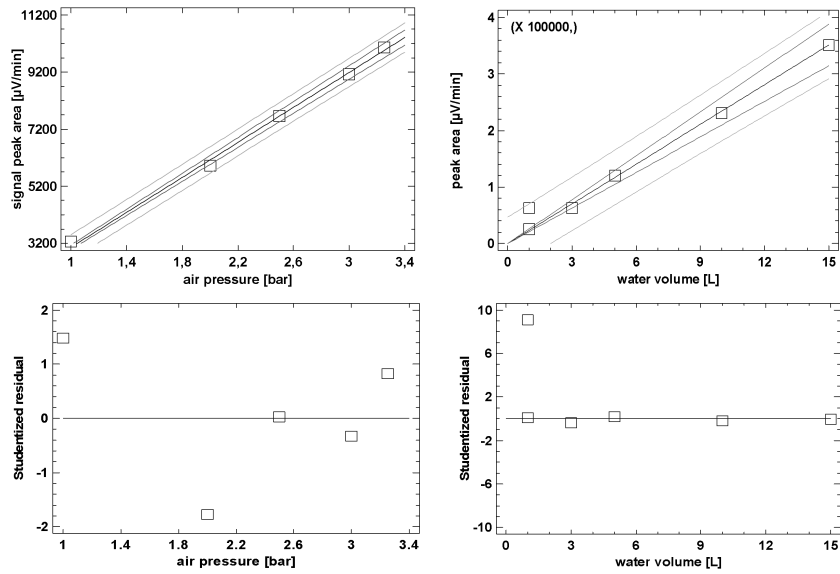

Figure 4. Assessment of linearity of the ECD signal towards Halon1301 using $10 \mathrm{~mL}$ modern air at different pressures (LEFT) and water at different volumes (RIGHT) showing an almost linear signal to pressure/volume (UPPER) and acceptable residuals (LOWER), lines in upper graphs represent the best least-square fit, fit with standard deviation of slope and $95 \%$ confidence interval.

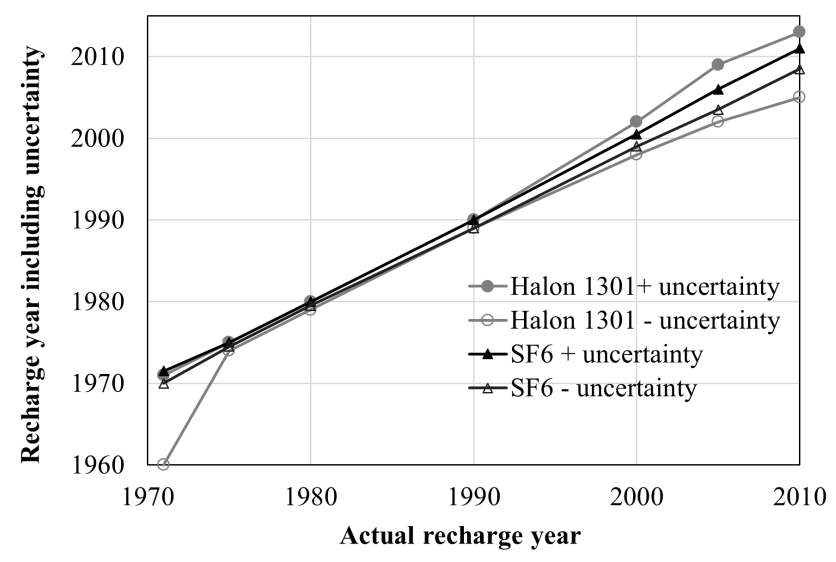

Figure 5. Effect of relative analytical uncertainty on inferred piston flow recharge year for $\mathrm{SF}_{6}$ and Halon-1301.

about 2000 when using Halon-1301, due to its characteristic S-shaped input function (Fig. 5). The LOD and LOQ of the analytical set-up was 0.32 and $0.98 \mathrm{fmol} \mathrm{L}^{-1}$ for Halon1301, respectively (and 0.23 and $0.69 \mathrm{fmol} \mathrm{L}^{-1}$ for $\mathrm{SF}_{6}$, respectively). The LOQ was equivalent to a recharge year of 1975 for Halon-1301, at average recharge temperature $\left(12.1^{\circ} \mathrm{C}\right), 10 \mathrm{~m}$ elevation and lack of excess air and headspace.

Sensitivity analysis showed that the most significant contributors to the overall uncertainty were uncertainties related to the calibration curve, repeatability, excess air and headspace correction for Halon-1301 and $\mathrm{SF}_{6}$. Without considering headspace and excess air, the total uncertainty became only marginally smaller for Halon-1301 (4.4 instead of $4.6 \%$ ), but significantly smaller for $\mathrm{SF}_{6}$ (3.2 instead of 
$9.0 \%$ ). Detailed determined uncertainties for each groundwater sample are shown in Figs. 6 and 7 and Table 3.

We note if $\mathrm{SF}_{6}$ alone was analysed using a different $\mathrm{GC}$ column it could be more accurately resolved with $4.5 \%$ overall uncertainty (van der Raaij and Beyer, 2015). However, our aim here was to simultaneously determine the two gaseous tracers $\mathrm{SF}_{6}$ and Halon-1301 with a particular focus on resolving the Halon-1301 signal accurately. The higher uncertainty in $\mathrm{SF}_{6}$ determination when using our approach may be resolved by adjustment of the column or ECD conditions or application of signal processing.

Please note that the analytical set-up also allows for simultaneous determination of CFC-12. This three way simultaneous determination of $\mathrm{SF}_{6}$, Halon-1301 and $\mathrm{CFC}-12$ may allow for more robust groundwater dating, due to the ability to identify issues related to the limited application range of the individual tracers. These are contact with air during sampling (indicated by an increased concentration of all three gas tracers), degradation/contamination (indicated by a reduced/increased concentration of one or more of the gas tracers, respectively) or unsaturated zone processes such as diffusion (lag time) or retardation (indicated by a reduced concentration of all or one or more of the gas tracers in comparison to tritium ages).

\subsection{Solubility}

To test the reported solubility of Halon-1301, we determined the Henry coefficient (Eq. S1 in the Supplement) in equilibrated tap and river water samples and in relatively young groundwater $(<2$ years MRT). These modern waters were collected for estimation of the solubility of Halon-1301. To estimate the robustness of the estimated Halon-1301 solubility, the solubility of $\mathrm{SF}_{6}$ was also determined in these samples with the same method and compared to literature data.

Figure 6 shows the inferred solubility $\left(\ln \mathrm{K}_{H}\right.$ ) of $\mathrm{SF}_{6}$ and Halon-1301 in modern groundwater and equilibrated tap and river water compared to solubilities estimated by Deeds (2008) and Bullister et al. (2002) for Halon-1301 and $\mathrm{SF}_{6}$, respectively. Table 1 contains solubility parameters inferred from the found relationship in Fig. 6 along with previously reported solubility parameters. As can be seen, inferred solubility of $\mathrm{SF}_{6}$ agreed well with its reported solubility, which indicated that our approach should give relatively robust Halon-1301 solubility estimates. Inferred solubility of Halon-1301 was significantly lower than estimated by Deeds (2008). When using the Deeds (2008) estimated solubility parameters, Halon-1301 concentrations were obtained which resulted in significantly older inferred Halon1301 ages compared to tritium and $\mathrm{SF}_{6}$ ages with an average discrepancy of +12 years in equilibrated tap and river water. This offset was removed when using our estimated Halon1301 solubility parameters.

Due to absence of robust solubility data of Halon-1301, we used the solubility parameters estimated in this study (Ta-

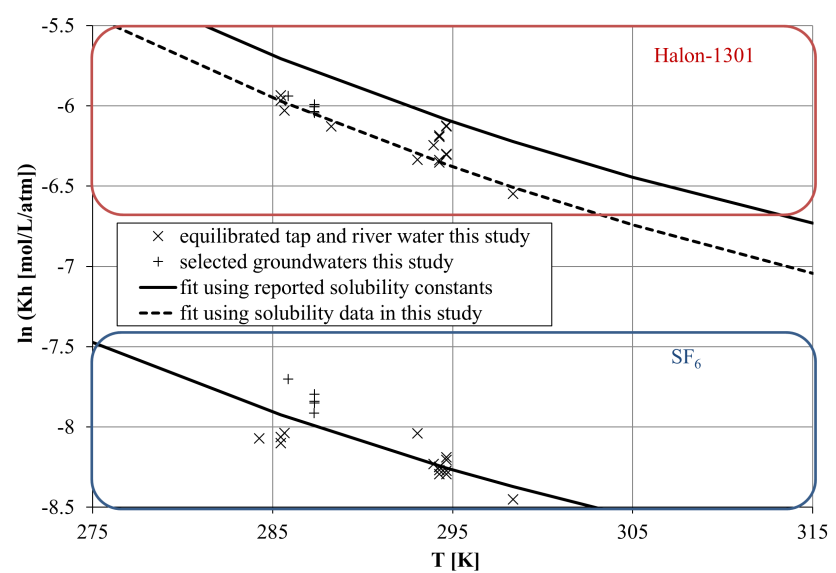

Figure 6. Estimated solubility of Halon-1301 and $\mathrm{SF}_{6}$ in equilibrated tap water, river water and oxic young groundwater in comparison to reported solubility data; ${ }^{*}$ using data from Deeds (2008) for Halon-1301 and Bullister et al. (2002) for $\mathrm{SF}_{6}$.

ble 3) to infer equivalent atmospheric Halon-1301 concentrations and with that infer Halon-1301 ages. Accurate measurement of the solubility of Halon-1301 is beyond the scope of this study. Due to the extremely low solubility of Halon1301, specialised equipment is required. The estimated solubility had a relatively large uncertainty of $9.8 \%$ (estimated for a regression analysis in Fig. 6), due to scatter in the data which may have been caused by uncertainty in recharge temperature, unaccounted heterogeneity, mixing of water, etc. The uncertainty in solubility added to the analytical uncertainty in equivalent atmospheric Halon-1301 concentration (estimated in the previous section), so that the overall uncertainty increased from 4.7 to $9.7 \%$. This increased uncertainty in turn affected the uncertainty in inferred Halon-1301 age as discussed in the following.

\subsection{Assessment of inferred Halon-1301 ages}

\subsubsection{Overall}

In the following we assessed inferred Halon-1301 mean ages in comparison to inferred $\mathrm{SF}_{6}$ and previously inferred tritium and CFC mean ages. We considered elevated concentrations of Halon-1301, $\mathrm{SF}_{6}$ or CFCs (>10\%) as "potentially contaminated" and highly elevated concentrations $(>25 \%)$ as "highly contaminated". Details on individual piston and exponential piston flow model MRTs inferred from Halon-1301 and $\mathrm{SF}_{6}$ (in this study) and tritium (from previous studies) are listed in Table 3.

Inferred $\mathrm{PM} \mathrm{SF}_{6}$ and Halon-1301 ages (illustrated in Fig. 7) showed that Halon-1301 ages were on average 5.4 years higher than inferred $\mathrm{SF}_{6}$ ages (over the entire age range), caused by reduced concentrations of Halon-1301 compared to $\mathrm{SF}_{6}$. However, piston flow ages are unrealistic, as they neglect mixing of water of different age in the subsur- 


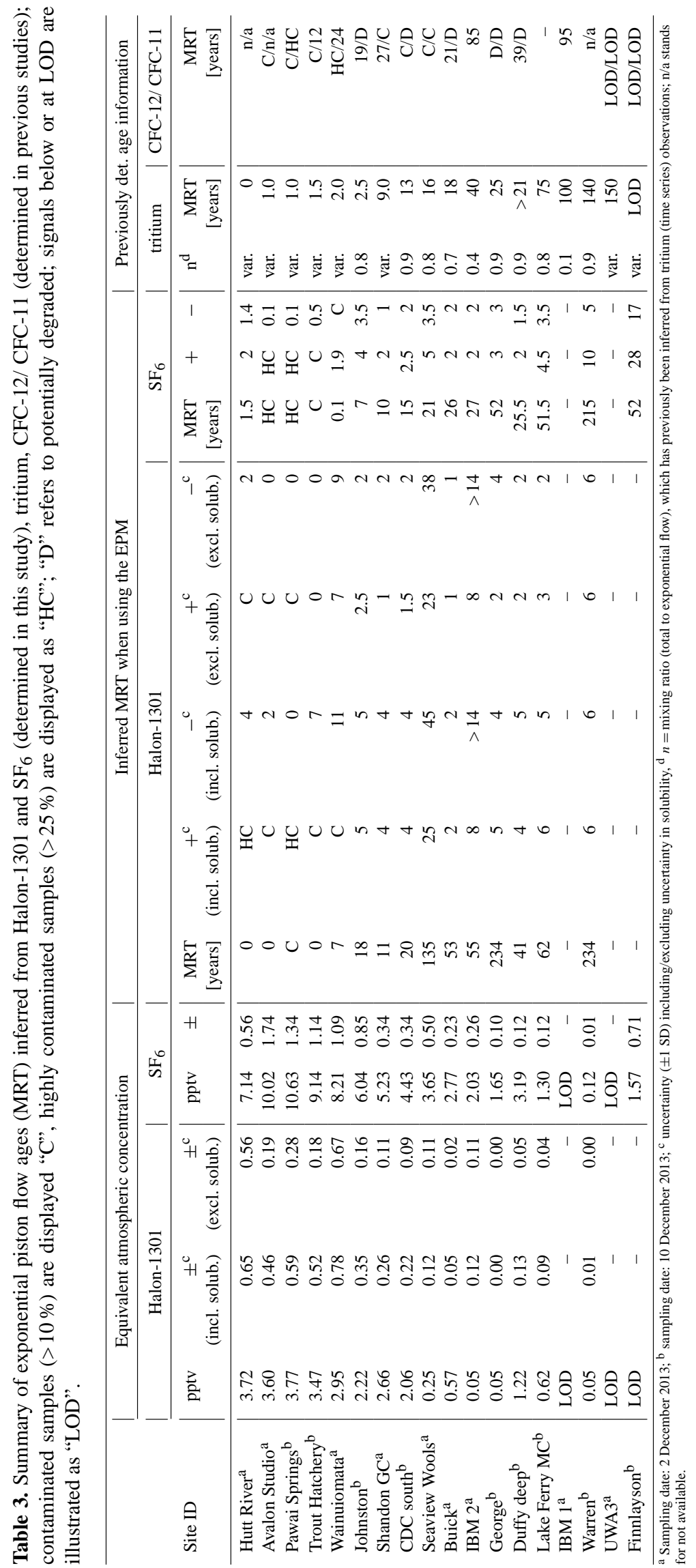




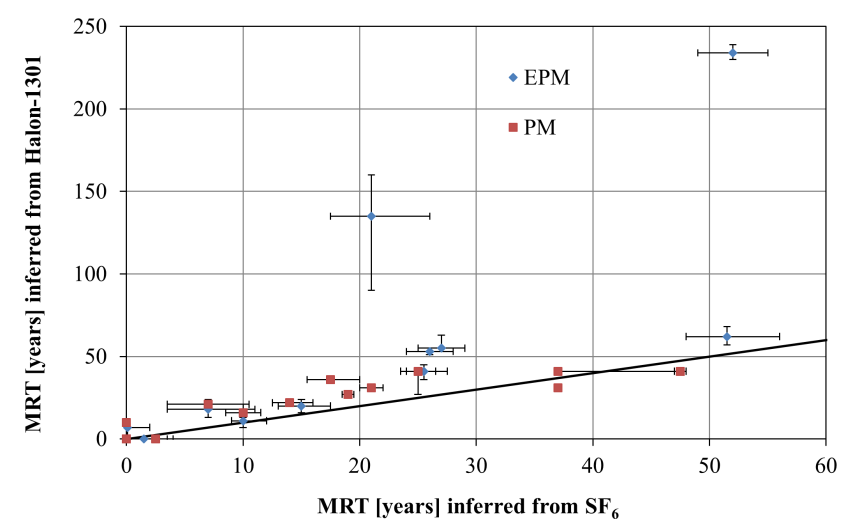

Figure 7. Piston flow and exponential piston flow ages (MRTs) inferred from Halon-1301 and $\mathrm{SF}_{6}$ concentrations, including error bars $( \pm 1$ SD analytical uncertainty including uncertainty in solubility).

face or during sampling (e.g. Małoszewski and Zuber, 1982), also indicated by previously determined EPM ages inferred from tritium and $\mathrm{SF}_{6}$ (e.g. Morgenstern and Taylor, 2009). In the following we applied an EPM and inferred MRTs from Halon-1301 and $\mathrm{SF}_{6}$ concentrations. The choice of lumped parameter model significantly affected the age interpretation with Halon-1301, due to its S-shaped input function, which is skewed due to mixing processes (depending on the lumped parameter model choice). This highlighted the importance of considering mixing processes for inferring groundwater age from Halon-1301 observations. For $\mathrm{SF}_{6}$, this was less of a problem, due to its nearly linear atmospheric input since the late 1980s. The sensitivity of Halon-1301 concentrations towards mixing of groundwater of different age also implied that groundwater dating with Halon-1301 may allow better constraining of the mixing parameters compared to $\mathrm{SF}_{6}$. However, time series Halon-1301 data are necessary to confirm this supposition.

\subsubsection{Consistency of inferred Halon-1301 ages with inferred tritium and $\mathrm{SF}_{6}$ ages using the EPM}

When using the EPM, inferred Halon-1301 and $\mathrm{SF}_{6}$ MRTs agreed for the majority of sites (for 12 out of 18 sites) as summarised in Table 3. Inferred MRTs were considered as agreeing (i.e. insignificantly different) when their uncertainty bounds of $1 \mathrm{SD}$ (except for one site where we accepted 1.1 SD) overlapped. The remaining sites indicated higher MRTs inferred from Halon-1301 compared to $\mathrm{SF}_{6}$. To assess whether these differences had been caused by processes affecting both gas tracers (such as lag time in the unsaturated zone) or only Halon-1301 (such as potential degradation or sorption which does not occur for $\mathrm{SF}_{6}$ ), inferred Halon-1301 and $\mathrm{SF}_{6}$ MRTs were compared to previously inferred tritium MRTs in Fig. 8. Where present, samples exhibiting probable CFC degradation/contamination are highlighted in Fig. 8 .

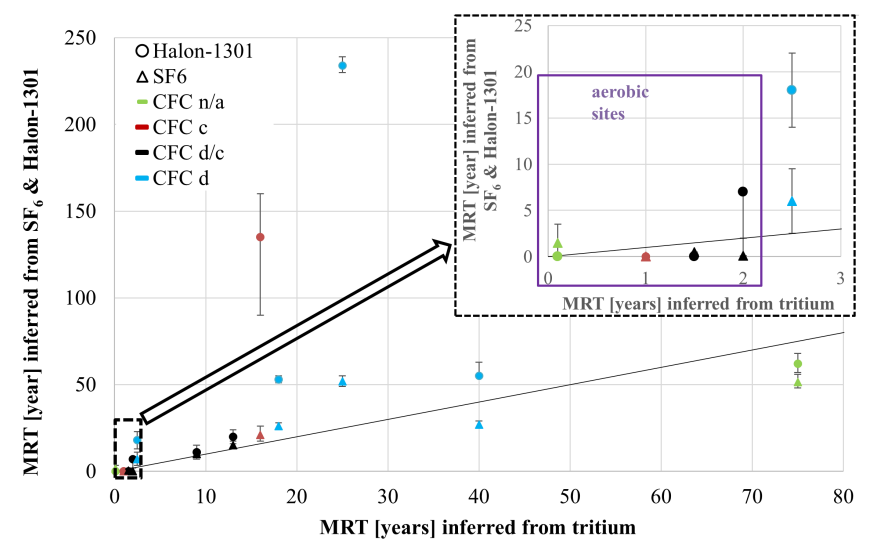

Figure 8. Summary of mean residence time including error bars $( \pm 1 \mathrm{SD}$ analytical uncertainty including uncertainty in solubility) inferred from Halon-1301, $\mathrm{SF}_{6}$ vs. mean residence times inferred from tritium using the exponential piston flow model, data points are highlighted according to CFC-12/CFC-11 contamination/degradation (see legend); Halon-1301 and $\mathrm{SF}_{6}$ were determined in this study, tritium and the CFCs were determined in previous study(s); the abbreviations " $c$ " and " $d$ " in the legend refer to contaminated and degraded in one or both CFCs, respectively; $\mathrm{c} / \mathrm{d}$ refers to contamination and degradation was observed for either CFC-12 or CFC-11; "n/a" refers to no available CFC data.

Comparison to inferred CFC ages could not be made, because all samples (with available CFC data) were degraded and/or contaminated in one or both of CFC-11 and CFC- 12 .

At one of the 18 sites, both gases and tritium were close to the LOD, but evidence of slight contamination with modern air during sampling was found, indicated by elevated concentrations of both $\mathrm{SF}_{6}$ and Halon-1301 which were incompatible with their low tritium concentrations. Evaluation of the performance of Halon-1301 as an age tracer in comparison to $\mathrm{SF}_{6}$ and tritium was not possible for this sample, which was therefore excluded for the overall comparison. For the majority of the remaining 17 groundwater samples, inferred $\mathrm{SF}_{6}$ ages agreed well with previously determined tritium ages, which indicated that unsaturated zone processes were not significant in this study.

Inferred Halon-1301 MRTs of 12 out of 17 sites were in agreement with inferred tritium and/or $\mathrm{SF}_{6}$ MRTs (within an uncertainty of $\sim 1 \mathrm{SD}$ ). This included four older groundwater sites, which showed concentrations at or close to LOD of tritium and $\mathrm{SF}_{6}$, and were also free of Halon-1301 (Fig. 9 and Table 3). For the remaining waters (all relatively old and anoxic), inferred Halon-1301 ages were higher compared to tritium $/ \mathrm{SF}_{6}$ ages. The reasons for this offset are discussed in the following subsection.

As can be seen in Table 3, the relatively large uncertainty in estimated solubility led to additional uncertainty in inferred Halon-1301 ages (compared to estimates assuming only a $1 \%$ uncertainty in solubility, for demonstration purposes). We found up to 16 years higher uncertainty in in- 

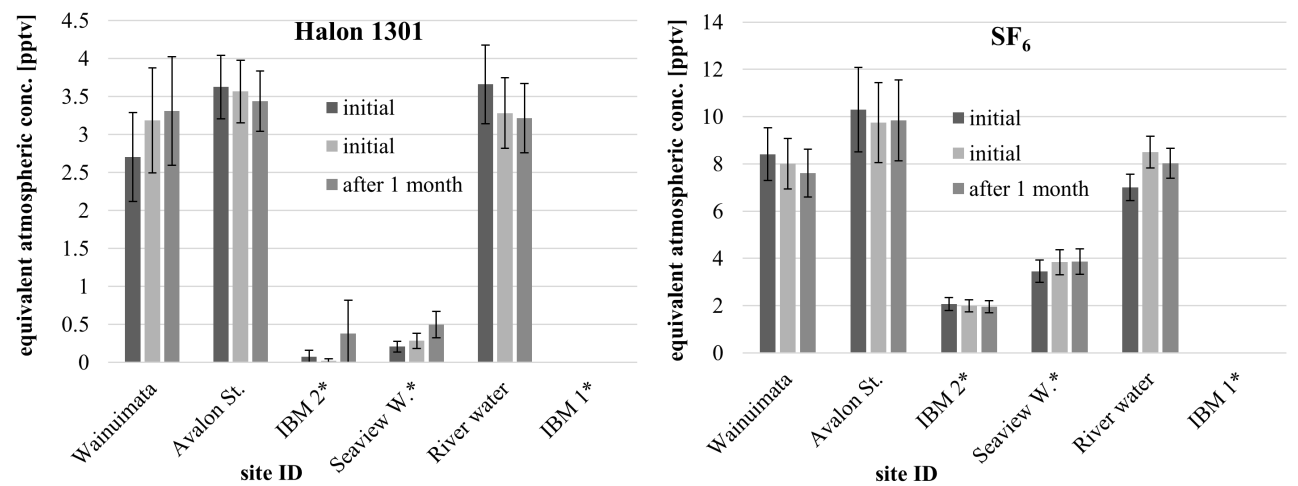

Figure 9. Comparison of Halon-1301 concentration in $1 \mathrm{~L}$ water samples analysed directly after sampling (2 of 3$)$ and after 7 weeks (1.2 years for Hutt River water sample) storage at $14{ }^{\circ} \mathrm{C}(1$ of 3$) ;{ }^{*}$ anoxic water samples.

ferred Halon-1301 MRTs when accounting for the current uncertainty in solubility. Inferred Halon-1301 ages can potentially be better constrained with a more accurate solubility estimate. This also means the full potential of Halon-1301 as an age tracer cannot yet be realised due to absence of accurate/robust solubility data.

\subsubsection{Conservativeness of Halon-1301}

No significantly elevated Halon-1301 concentrations were found, despite that the sites cover situations of land use and well construction that result in CFC contamination. A significantly elevated Halon-1301 concentration was only found for one site in concert with an elevated $\mathrm{SF}_{6}$ concentration, suggesting that the sample was contaminated with air during sampling (Fig. 8 and Table 3). This indicated no issues related to contamination for Halon-1301 from local sources at the studied sites. This has to be evaluated further, e.g. in groundwater recharged close to airports, where Halon-1301 is still in use as a fire suppressant during fuelling of planes. The lack of elevated Halon-1301 concentrations may also indicate that interference of the Halon-1301 signal with CFC13 or other co-eluting compounds (as has been assessed in Beyer et al., 2014b) was not an issue in the studied groundwater samples. However, this needs to be assessed further in groundwater with elevated concentrations of CFC-13 or other potentially co-eluting compounds.

Significantly higher Halon-1301 MRTs to tritium and $\mathrm{SF}_{6}$ MRTs (over an age range from 2.5 to 40 years MRT) were found in 5 of the 17 groundwater samples, where direct age comparison could be made. These samples also showed evidence of significant (even higher) degradation and/or contamination of one or both of CFC-11 and CFC-12. There are several possibilities for higher inferred Halon-1301 groundwater ages as a result of reduced Halon-1301 concentrations, which we assessed in detail in Supplement Sect. S2. A summary is presented in the following. Our assessment showed we could exclude degassing into headspace created by denitrification, production of methane or when groundwater is brought to the ground surface, since this would have affected all determined gas tracers, to the highest extend the least water soluble $\mathrm{SF}_{6}$, which we did not find in any of our samples. We could also exclude lag time in the unsaturated zone, because this would have also affected all gas tracers, dependent on their diffusion coefficient (Gooddy et al., 2006) and we did not find decreased concentrations of both Halon-1301 and $\mathrm{SF}_{6}$ in any of our samples. Assuming that Halon-1301 behaved similarly to CFCs in regards to sorption to specific materials, we also considered the risk of sorption to well casing/sampling material was minimal as we followed a robust sampling procedure established for CFCs and $\mathrm{SF}_{6}$ (using only borosilicate glass, stainless steel equipment and nylon tubing).

Potential degradation of Halon-1301 during storage was assessed by analysis of six groundwater samples from different sites (covering an age range from modern $(<1$ year) to over 100 years MRT, and oxic to anoxic waters) stored for 7 weeks. The simultaneous determination of $\mathrm{SF}_{6}$ and Halon-1301 allowed us to isolate Halon-1301 degradation, since $\mathrm{SF}_{6}$ is not known to degrade in oxic or anoxic environments. Hence, an isolated reduced concentration in Halon1301 would indicate Halon-1301 degradation, in contrast to a combined (Halon-1301 and $\mathrm{SF}_{6}$ ) reduced concentration that would indicate, e.g., escaping of gas into headspace. Figure 9 illustrates concentrations determined before and after storage were within statistical uncertainty, indicating that Halon1301 was stable in oxic and anoxic groundwater during storage for over 1 month at $14^{\circ} \mathrm{C}$. The concentration of Halon1301 in one sample (river water) stored for over 1.2 years was also not significantly reduced compared to $\mathrm{SF}_{6}$.

The remaining possibilities for reduced Halon-1301 concentrations (i.e. increased inferred ages) were the following:

1. Increased inferred Halon-1301 ages in younger water samples with a MRT (tritium age) close to or below 15 years (applicable for 1 of 5 affected samples) were likely caused by uncertainties related to the recent levelling out atmospheric concentrations of Halon-1301 
(AGAGE, 2014), which made it more difficult to constrain the age of younger waters.

2. Increased inferred Halon-1301 ages in the remaining, particularly older samples with a MRT above 15 years were likely caused by (a) degradation, which is only likely to occur under anoxic/anoxic conditions (all affected samples are anoxic); (b) sorption to organic material in the aquifer (could not be excluded for any of the sites).

Further studies are needed to confirm whether Halon1301 is degradable or reduced concentrations are a result of sorption/retardation in the aquifer. This can be studied by determination of Halon-1301 in relatively old (MRT of $>5$ years) oxic groundwater and/or relatively young (MRT $<5$ years) anoxic groundwater. Reduced concentrations of Halon-1301 in relatively old oxic water could confirm sorption/retardation, since degradation is likely only occurring in anoxic water. Similarly, analysis of relatively young anoxic/anoxic groundwater where sorption/degradation has not likely affected the concentration of Halon-1301 (due to a relatively short travel time in the aquifer and the currently levelling out atmospheric trend) could confirm degradation of Halon-1301 if reduced concentrations are found.

\section{Summary and conclusion}

This paper provided an insight into the suitability of the gaseous, water soluble compound Halon-1301 as groundwater age tracer. We demonstrated the capability of the analytical set-up for robust simultaneous determination of the gas tracers Halon-1301 and $\mathrm{SF}_{6}$ (and CFC-12) on the same $1 \mathrm{~L}$ water sample, which provided an immense potential for more robust age interpretation of relatively young groundwater (recharged $<100$ years). We estimated solubility, which is required to convert measured concentrations in water into atmospheric concentrations, from a range of equilibrated waters and relatively modern, oxic groundwater. We found that the solubility of Halon-1301 found in this study did not match its reported solubility. Uncertainties arising from this estimation approach, led to higher uncertainty in inferred MRT up to 16 years. More accurate determination of the solubility of Halon-1301 is required for better utilisation of its potential as age tracer.

We used piston and exponential piston flow modelling (PM and EPM) to infer age from Halon-1301 (and $\mathrm{SF}_{6}$ ) concentrations in groundwater. Significantly different age interpretations were found with both modelling approaches. Halon-1301 was particularly sensitive to the choice of LPM due to its $\mathrm{S}$-shaped input function, which is considerably skewed during mixing processes in contrast to $\mathrm{SF}_{6}$ with a nearly linear atmospheric record. This indicated that the determination of Halon-1301 may allow for a better constraint of the mixing model. However, further study is needed to support this supposition with time series Halon-1301 data. Previously inferred $\mathrm{CFC}, \mathrm{SF}_{6}$ and tritium ages in the studied groundwater sites allowed us to compare the performance of Halon-1301 as an age tracer compared to other tracers.

Twelve of 17 groundwater samples, where direct comparison of inferred ages could be made, showed matching Halon-1301, $\mathrm{SF}_{6}$ and/or tritium ages within an uncertainty of $\sim 1$ SD. We found no significantly increased Halon-1301 concentrations in any of the analysed groundwater samples which indicated no apparent sources of contamination of Halon-1301 in our study, despite the fact that the sites included different land use environments and well construction that resulted in CFC contamination. This also indicated that interference with other co-eluting compounds was not an issue, since this would have led to increased concentrations of Halon-1301 determined in water.

Analysis of stored groundwater samples indicated that Halon-1301 was stable in oxic to anoxic water stored up to 7 weeks at $14{ }^{\circ} \mathrm{C}$. Reduced concentration of Halon-1301 (along with significantly even further reduced concentration of CFC-12 and -11) at 5 of 17 sites needs to be assessed further. It is unclear if reduced concentrations were caused by degradation or retardation of Halon-1301 in the aquifer.

Despite these not fully understood reduced concentrations, we showed that Halon-1301 has strong potential as a complementary groundwater age tracer. If used in combination with other established tracers, it is likely to aid in reducing the ambiguity in groundwater age interpretations obtained though tritium, $\mathrm{SF}_{6}$ and fading out $\mathrm{CFC}$ concentrations, and improve constraining mixing models. Since Halon-1301 is a gaseous tracer, it has additional potential to be used to assess unsaturated as well as saturated zone processes, especially with respect to the simultaneous determination of CFC-12 and $\mathrm{SF}_{6}$ on the proposed analytical set-up. Due to its $\mathrm{S}$-shaped, fading out atmospheric input and analytical detection limits, we suggest the appropriate application range for inference of groundwater age from Halon-1301 is for waters recharged between 1980 and 2005/2008. Higher uncertainty will be present in age estimates for waters of earlier (from 1970s) or more modern recharge. The uncertainty in inferred Halon-1301 age can be reduced by more accurate determination of its solubility.

To confirm the absence of local contamination sources, Halon-1301 needs to be assessed further at sites with higher risk of local sources (e.g. close to airports). To assess whether reduced Halon-1301 concentrations in older anoxic waters are a result of degradation or sorption, Halon-131 needs to be assessed in anoxic waters (preferably young MRT $<5$ years) that have been influenced by different compositions of bacteria and/or aquifer material, and/or in relatively old oxic sites (MRT > 5 years) with high organic content. Even if Halon-1301 is affected by degradation/sorption and/or contamination is occurring in specific areas, Halon1301 is likely to be a more reliable groundwater age tracer than CFCs, which face issues regarding their reliability to in- 
fer groundwater age due to (anthropogenic) contamination and degradation in anoxic waters, as we observed in this study. Concentrations in the atmosphere are also fading out, which will make CFCs even less reliable in the future.

We suggest that Halon-1301 (or any other tracer) is used complementarily together with other tracers, to compensate for individual tracer limitations. We do not suggest that Halon-1301 is used as a stand-alone tracer (although in our study area it was significantly more reliable than CFCs, which are commonly used alone in the literature). Specifically, we recommend the simultaneous determination of Halon-1301 with $\mathrm{SF}_{6}$ and CFC-12, using the cost-effective method presented in this study. This allows for the determination of three complementary age tracers in the same water sample, which may enable more precise determination of groundwater age (and mixing), assessment of unsaturated zone processes and increase robustness as the three tracers together allow identification and exclusion of problem samples, e.g. where contact with air has occurred during sampling, or where degradation of one or more of the age tracers has occurred.

\section{The Supplement related to this article is available online at doi:10.5194/hess-19-2775-2015-supplement.}

Acknowledgements. Greater Wellington Regional Council, especially Sheree Tidswell, is thanked for support and organisation of the sampling of the groundwater wells. Thanks to NIWA, especially Rowena Moss and Ross Martin, for provision of the NZIG Halon-1301, $\mathrm{SF}_{6}$ standard gas mixture. This study is part of a PhD supported by GNS Science as part of the Smart Aquifer Characterization programme funded by the New Zealand Ministry for Science and Innovation (http://www.smart-project.info/).

Edited by: M. Hrachowitz

\section{References}

AGAGE (Advanced Global Atmospheric Gases Experiment): atmospheric SF6 data available at: http://agage.eas.gatech.edu/data archive/agage/gc-ms-medusa/monthly/CGO-medusa.mon (last access: 14 February 2014), 2014.

Allison, G. B. and Hughes, M. W.: The use of environmental chloride and tritium to estimate total recharge to an unconfined aquifer, Aust. J. Soil Res., 16, 181-195, 1978.

Barletta, B., Nissenson, P., Meinardi, S., Dabdub, D., Sherwood Rowland, F., VanCuren, R. A., Pederson, J., Diskin, G. S., and Blake, D. R.: HFC-152a and HFC-134a emission estimates and characterization of CFCs, CFC replacements, and other halogenated solvents measured during the 2008 ARCTAS campaign (CARB phase) over the South Coast Air Basin of California, Atmos. Chem. Phys., 11, 2655-2669, doi:10.5194/acp-11-26552011, 2011.
Bartyzel, J.: Wykorzystanie środowiskowych znaczników gazowych (SF6, SF5CF3, CCl2F2, CBrF3) do datowania wód podziemnych - zagadnienia metodyczne i zastosowania, PhD thesis, Wydziału Geologii, Geofizyki i Ochrony Środowiska AGH, University of Science and Technology in Kraków, 2015.

Begg, J., Brown, L., Gyopari, M., and Jones, A.: A review of Wairarapa geology - with a groundwater bias. Institute of Geological and Nuclear Sciences Client Report 2005/159, Wellington, New Zealand, 2005.

Beyer, M., Morgenstern, U., and Jackson, B.: Review of dating techniques for young groundwater ( $<100$ years) in New Zealand, J. Hydrol. New Zealand, 53, 93-111, 2014a.

Beyer, M., van der Raaij, R., Morgenstern, U., and Jackson, B.: Potential groundwater age tracer found: Halon-1301 (CF3Br), as previously identified as CFC-13 (CF3Cl), Water Resour. Res., 50, 7318-7331, doi:10.1002/2014WR015818, 2014 b.

Bullister, J. (NOAA/PMEL): Atmospheric CFC-11, CFC-12, CFC113, CCl4 and SF6 Histories (1910-2011), Ocean $\mathrm{CO}_{2}$, carbon dioxide information analysis centre, available at: http:// cdiac.ornl.gov/oceans/new_atmCFC.html (last access: 1 October 2012), 2011.

Bullister, J. L. and Lee, B. S.: Chlorofluorocarbon-11 removal in anoxic marine waters, Geophys. Res. Lett., 22, 1893-1896, doi:10.1029/95GL01517, 1995.

Bullister, J. L., Wisegarver, D. P., and Menzia, F. A.: The solubility of sulfur hexafluroide in water and sewater, Deep-Sea Res. I, 49, 175-188, 2002.

Busenberg, E. and Plummer, L. N.: Dating young groundwater with sulphur hexafluoride: natural and anthropogenic sources of sulfur hexafluoride, Water Resour. Res., 36, 3011-3030, 2000.

Busenberg, E. and Plummer, N.: Dating groundwater with trifluoromethyl sulfurpentafluoride (SF5CF3), sulfurhexafluoride (SF6), CF3Cl (CFC-13) \& CF2CL2 (CFC-12), Water Resour. Res., 44, W02431, doi:10.1029/2007WR006150, 2008.

Busenberg, E. and Plummer, L. N.: A rapid method for the measurement of sulfur hexafluoride (SF6), trifluoromethyl sulfur pentafluoride (SF5CF3), and Halon 1211 (CF2ClBr) in hydrologic tracer studies, Geochem. Geophy. Geosy., 11, doi:10.1029/2010GC003312, 2010.

Butler, J., Elkins, J., Thompson, T., Hall, B., Swanson, T., and Koropalov, V.: Oceanic consumption of $\mathrm{CH} 3 \mathrm{CCI} 3$; implications for tropospheric OH, J. Geophys. Res., 96, 22347-22355, 1991.

Butler, J. H., Battle, M., Bender, M. L., Montzka, S. A., Clarke, A. D., Saltzman, E. S., Sucher, C. M., Severinghaus, J. P., and Elkins, J. W.: A record of atmospheric halocarbons during the twentieth century from polar firn air, Nature, 399, 749-755, 1999.

Butler, J. H., Montzka, S. A., Clarke, A. D., Lobert, J. M., and Elkins, J. W.: Growth and distribution of halons in the atmosphere, J. Geophys. Res., 103, 1503-1511, doi:10.1029/97JD02853, 1998.

Cook, P. G. and Solomon, D. K.: Transport of atmospheric trace gases to the water table: Implications for groundwater with chlorofluorocarbons and dating krypton 85, Water Resour. Res., 31, 263-270, doi:10.1029/94WR02232, 1995.

Cook, P. G., Plummer, N. L., Solomon, D. K., Busenberg, E., and Han, L. F.: Effects and processes that can modify apparent CFC age, in: Use of chlorofluorocarbons in hydrology, IAEA, Vienna, 31-58, 2006. 
Caulcutt, R. and Boddy, R.: Statistics for Analytical Chemist, Champman and Hall, London, 1983.

Daughney, C. Jones. J., Baker, T., Hanson, C., Davidson, P., Zemansky, G., Reeves, R., and Thompson, M.: A National Protocol for State of the Environment Groundwater Sampling in New Zealand, ME report 781, Ministry for the Environment Wellington, New Zealand, 2006.

Deeds, D. A.: The Natural Geochemistry of Tetrafluoromethane and Sulfur Hexafluoride: Studies of Ancient Mojave Desert Groundwaters, North Pacific Seawaters and the Summit Emissions of Kilauea Volcano, PhD Dissertation, University of California, San Diego, 2008, available as Scripps Institution of Oceanography Technical Report, Scripps Institution of Oceanography, UC, San Diego, http://www.escholarship.org/uc/item/1hp1f3bd (last access: 29 November 2014), 2008.

Eberts, S. M., Böhlke, J. K., Kauffman, L. J., and Jurgens, B. C.: Comparison of particle-tracking and lumped-parameter agedistribution models for evaluating vulnerability of production wells to contamination, Hydrogeol. J., 20, 263-282, 2012.

Edmunds, W. M. and Walton, N. R. G.: A geochemical and isotopic approach to recharge evaluation in semi-arid zones, past and present, Arid Zone Hydrology, Investigations with Isotope Techniques, IAEA, Vienna, 47-68, 1980.

Ellison, S. L. R. and Williams, A. (Eds.): EURACHEM/CITAC Guide CG4. Quantifying Uncertainty in Analytical Measurement, 3rd Edn., Eurachem, Austria, ISBN 978-0-948926-30-3, available at: www.eurachem.org (last access: 15 March 2015), 2012.

Engesgaard, P., Jensen, K. H. Molson, J. Frind, E. O., and Olsen, H.: Large-Scale Dispersion in a Sandy Aquifer: Simulation of Subsurface Transport of Environmental Tritium, Water Resour. Res., 32, 3253-3266, doi:10.1029/96WR02398, 1996.

EU Legislature: Directive 2000/60/EC of the European Parliament and of the Council of 23 October 2000 establishing a framework for the Community action in the field of water policy, http://ec.europa.eu/environment/water/water-framework/ index_en.html (last access: 10 June 2015), 2000.

Gooddy, D., Darling, G., Abesser, C., and Lapworth, D. J.: Using chlorofluorocarbons (CFCs) and sulphur hexafluoride (SF6) to characterise groundwater movement and residence time in a lowland Chalk catchment, J. Hydrol., 330, 44-52, doi:10.1016/j.jhydrol.2006.04.011, 2006.

Grabczak, J., Maloszewski, P., Rozanski, K., and Zuber, A: Estimation of the tritium input function with the aid of stabile isotopes, Catena, 11, 105-114, 1984.

Grant-Taylor, T. L.: Groundwater in New Zealand, NZGS report 24, presented at "Water of Peace" conference, 23 to 31 May 1967, Washington, 1967.

Gyopari, M.: Lower Hutt Aquifer Model Revision (HAM3): Sustainable Management of the Waiwhetu Aquifer, Earth in Mind Ltd report prepared for Greater Wellington Regional Council, June 2014, Wellington, New Zealand, 2014.

Heaton, T. H. E. and Vogel, J. C.: "Excess air" in groundwater, J. Hydrol., 50, 201-216, 1981.

Helsel, D. R. and Hirsch, R. M.: Statistical Methods in Water Resources Techniques of Water Resources Investigations, Book 4, chapter A3, U.S. Geological Survey, 522 pp., 2002.
Jones, A. and Barker, T.: Groundwater monitoring technical report, Greater Wellington Regional Council, Publication No. GW/RINV-T-05/86, Wellington, 2005.

Jones, A. and Gyopari, M.: Regional conceptual and numerical modelling of the Wairarapa groundwater basin, Technical Report GW/EMI-T-06/293, Greater Wellington Regional Council, 2006.

Jurgens, B. C., Böhlke, J. K., and Eberts, S. M.: TracerLPM (Version 1): An Excel ${ }^{\circledR}$ workbook for interpreting groundwater age distributions from environmental tracer data: U.S. Geological Survey Techniques and Methods Report 4-F3, 60 pp., U.S. Geological Survey, Reston, Virginia, 2012.

Kanta Rao, P., Rama Rao, K. S., and Hari Padmasri, A.: Transformation of chlorofluorocarbons through catalytic hydrodehalogenation, CATTECH, 7, 218-225, 2003.

Knott, J. F. and Olimpio, J. C.: Estimation of Recharge Rates to the Sand and Gravel Aquifer Using Environmental Tritium, Nantucket Island, Massachusetts, U.S. Geological Survey, WaterSupply Paper 2297, Denver, CO, US, 2001.

Koh, D. C., Plummer, N. L., Busenberg, E., and Kim, Y.: Evidence for terrigenic SF6 in groundwater from basaltic aquifers, Jeju Island, Korea: Implications for groundwater dating, J. Hydrol., 339, 93-104, 2007.

Kragten, J.: Calculating standard deviations and confidence intervals with a universally applicable spreadsheet technique, Analyst, 119, 2161-2166, 1994.

Lesage, S., Jackson, R. E., Priddle, M. W., and Riemann, P. G.: Occurrence and fate of organic solvent residues in anoxic groundwater at the Gloucester landfill, Canada, Environ. Sci. Technol., 24, 559-566, 1990.

Maiss, M. and Brenninkmeijer, C. A. M.: Atmospheric SF6: Trends, sources and prospects, Environ. Sci. Technol., 32, 3077-3086, 1998.

Małoszewski P. and Zuber A.: Determining the turnover time of groundwater systems with the aid of environmental tracers, J. Hydrol., 5, 207-231, 1982.

Meylan, W. M. and Howard, P. H.: Bond contribution method for estimating henry's law constants, Environ. Toxicol. Chem., 10, 1283-1293, doi:10.1002/etc.5620101007, 1991.

Meylan, W. M., Howard, P. H., and Boethling, R. S.: Improved method for estimating water solubility from octanol/water partition coefficient, Environ. Toxicol. Chem., 15, 100-106, doi:10.1002/etc.5620150205, 1996.

Miller, B. R., Weiss, R. F., Salameh, P. K., Tanhua, T., Greally, B. R., Mühle, J., and Simmonds, P. G.: Medusa: A sample preconcentration and GC/MS detector system for in situ measurements of atmospheric trace halocarbons, hydrocarbons, and sulfur compounds, Anal. Chem., 80, 1536-1545, 2008.

Ministry of Health: Drinking-water Standards for New Zealand 2005 (revised 2008), Ministry of Health, Wellington, New Zealand, available at: http://www.health.govt.nz/system/files/ documents/publications/drinking-water-standards-2008_0.pdf (last access: 15 July 2013), 163 pp., 2008.

Montzka, S. A. and Fraser, P. J.: Controlled substances and other gases, in scientific Assessment of Ozone Depletion: 2002, World Meteorol. Org., Geneva, 1-87, 2003.

Morgenstern, U. and Taylor, C. B.: Ultra low-level tritium measurement using electrolytic enrichment and LSC, Isot. Environ. Healt. S., 45, 96-117, 2009. 
Morgenstern, U., Stewart, M. K., and Stenger, R.: Dating of streamwater using tritium in a post nuclear bomb pulse world: continuous variation of mean transit time with streamflow, Hydrol. Earth Syst. Sci., 14, 2289-2301, doi:10.5194/hess-14-22892010,2010

Newland, M. J., Reeves, C. E., Oram, D. E., Laube, J. C., Sturges, W. T., Hogan, C., Begley, P., and Fraser, P. J.: Southern hemispheric halon trends and global halon emissions, 1978-2011, Atmos. Chem. Phys., 13, 5551-5565, doi:10.5194/acp-13-55512013, 2013.

Oster, H., Sonntag, C., and Munnich, K. O.: Groundwater age dating with chlorofluorocarbons, Water Resour. Res., 32, 29893001, 1996.

Plummer, L. N. and Busenberg, E.: Chlorofluorocarbons, in Cook, P., and Herczeg, A., eds., Environmental tracers in subsurface hydrology: Boston, Mass., Kluwer Academic Publishers, Boston, 441-478, 1999

Reynolds, G. W., Hoff, J. T., and Gillham, R. W.: Sampling bias caused by materials used to monitor halocarbons in groundwater, Environ. Sci. Technol., 24, 135-142, 1990.

Reynolds, T. I.: Computer modelling of groundwater and evaluation of scenarios for pumping from the Waiwhetu Aquifer, Lower Hutt basin, Wellington Regional Council Publication No. WRC/CI-G-93/45, vol. 1-3, 142 pp., 1993.

Shapiro, S. D., Schlosser, P., Smethie, W. M., and Stute, M.: The use of H-3 and tritiogenic He-3 to determine CFC degradation and vertical mixing rates in Framvaren Fjord, Norway, Mar. Chem., 59, 141-157, 1997.

Shrivastava, A. and Gupta, V. B.: Methods for the determination of limit of detection and limit of quantitation of the analytical methods, Chronicles of Young Scientists, 2, 21, 21-25, doi:10.4103/2229-5186.79345, 2011.

Stewart, M. and Morgenstern, U.: Age and Source of Groundwaters from Isotopic Tracers, in: Groundwaters of New Zealand, edited by: Rosen, M. R. and White, P. A., Wellington, New Zealand, 161-183, 2001.
Stewart, M. K. and Taylor, C. B.: Environmental isotopes in New Zealand hydrology; 1 . Introduction. The role of oxygen-18, deuterium, and tritium in hydrology, New Zea. J. Sci., 24, 295-311, 1981.

Sturges, W., Baring, T., Butler, J., Elkins, J., Hall, B., Myers, R., Montzka, S., Swanson, T., and Thompson, T.: Nitrous Oxide and Halocarbons Group, Section 7 in: Climate Monitoring and Diagnostics Laboratory, No. 19 Summary Report 1990, edited by: Ferguson, E. and Rosson, R., US Department of Commerce, NOAA-ERL, Boulder, Colorado, USA, 63-71, 1991.

Taylor, C. B., Brown, L. J., Cunliffe, J. J., and Davidson, P. W.: Environmental tritium and $18 \mathrm{O}$ applied in a hydrological study of the Wairau Plain and its contributing mountain catchments, Marlborough, New Zealand, J. Hydrol., 138, 269-319, 1992.

Thompson, T. M., Butler, J. H., Daube, B. C., Dutton, G. S., Elkins, J. W., Hall, B. D., Hurst, D. F., King, D. B., Kline, E. S., Lafleur, B. G., Lind, J., Lovitz, S., Mondeel, D. J., Montzka, S. A., Moore, F. L., Nance, J. D., Neu, J. L., Romashkin, P. A., Scheffer, A., and Snible W. J.: Halocarbons and other Atmospheric Trace Species. Climate Monitoring and Diagnostics Laboratory Summary Report No. 27. Ch 5., Boulder, Colorado, NOAA (National Oceanic and Atmospheric Administration), 2004.

Tidswell, S., Conwell, C., and Milne, J. R.: Groundwater quality in the Wellington Region: State and trends, Greater Wellington Regional Council, Publication No. GW/EMI-T-12//140, Wellington, 2012.

van der Raaij, R. and Beyer, M.: Use of CFCs and SF6 as groundwater age tracers in New Zealand, J. Hydrol. New Zealand, 54, in press, 2015.

Visser, A.: Trends in groundwater quality in relation to groundwater age, $\mathrm{PhD}$ thesis, Netherlands Geographical Studies 384, Faculty of Geosciences, Utrecht University, the Netherlands, 2009.

Wilhelm, E., Battino, R., and Wilcock, R. J.: Low pressure solubility of gases in liquid water, Chem. Rev., 77, 219-262, 1977.

WRC (Wellington Regional Council): Wainuiomata Water Resource Statement, Wellington Regional Council publication WRC/PP-T-93/15, Wellington, New Zealand, 1993. 